\title{
Dynamic Analysis of Power System with Photovoltaic Generation
}

\author{
Chia-Yu Hsu ${ }^{1, a}$, Pei-Hwa Huang ${ }^{1}$ and Kai-Sheng Yang ${ }^{1}$ \\ ${ }^{1}$ Department of Electrical Engineering, National Taiwan Ocean University, Taiwan
}

\begin{abstract}
With more penetration of solar power plants, photovoltaic generation will be exerting more influences on the power system. The main purpose of this paper is to study the dynamic characteristics of the power system with photovoltaic generation. First, power flow and bus voltage variations of the system with photovoltaic generation are calculated. Then according to the related interconnection criteria, the voltage variation and cable loading are inspected to determine whether the system complies with relevant specifications. Finally, the dynamic responses of the system are analyzed. This paper focuses on a sample power system with photovoltaic generation. The system dynamic characteristics are examined when three-phase faults occur, and the system voltage variations subject to illumination change are investigated. Results show that photovoltaic generation has less impact on system because the capacity of the photovoltaic generation is not high. The illumination change does affect both voltage and frequency of the system, and the system will return to a normal operating state after a period of time.
\end{abstract}

\section{Introduction}

Because of some challenges such as conventional energy sources consumption, pollution, global climate change and security of energy supply, significant efforts have been made to develop renewable energy sources such as solar energy, wind energy, and hydraulic energy. As a result, worldwide, there has been a move to significantly increase the utilization of environment friendly renewable resources and to increase the reliability of power supplied to the customers, and if possible, reduce losses in transmission and distribution systems [1]. One way of generating electricity from renewable sources is to use photoelectric cell that convert the energy of light directly into electricity [2].

The latest technological advancements in solar energy conversion and the increased support from government and private institutions have led to increased photovoltaic generation in recent years. Thus photovoltaic (PV) generation exert more influences on the system and the regulation of parallel operation for the photovoltaic generation has been becoming more and more stringent [3-6]. The main purpose of this paper is to study the analysis of the dynamic characteristics problem of power system with photovoltaic generation.

The major research work is focus on the detailed investigation of system dynamic characteristics with a sample power system as study cases. The system dynamic characteristics are examined when three-phase faults occur, and the system voltage variations subject to illumination change are investigated.

\section{Overview of photovoltaic generation}

Photovoltaic generation is a use of light energy into power, also known as photovoltaic cells. Photovoltaic

\footnotetext{
a Corresponding author:20053003@mail.ntou.edu.tw
}

power generation employs solar panels composed of a number of solar cells containing a photovoltaic material. Most of the solar cells are semiconductor material. Accordance with the chemical formula can be divided into silicon semiconductor and compound semiconductor. The main practical application of the silicon material battery, can be divided into stacking (Bulk Type) and Thin Film (Thin Film Type). Materials presently used for photovoltaic include monocrystalline silicon, polycrystalline silicon, amorphous silicon and cadmium telluride [7]. As there are many kinds of the production of materials, the manufacture of solar cells with conversion efficiency are also different.

\section{Dynamic model of photovoltaic generation}

\subsection{Mathematical modelling of photovoltaic generation}

A photovoltaic cell is based on the physical phenomenon called "photovoltaic effect". Figure 1 shows the equivalent circuit model of a PV module [7, 8]. This circuit model is composed of an ideal current source, a diode connected in parallel with the current source and a series resistor.

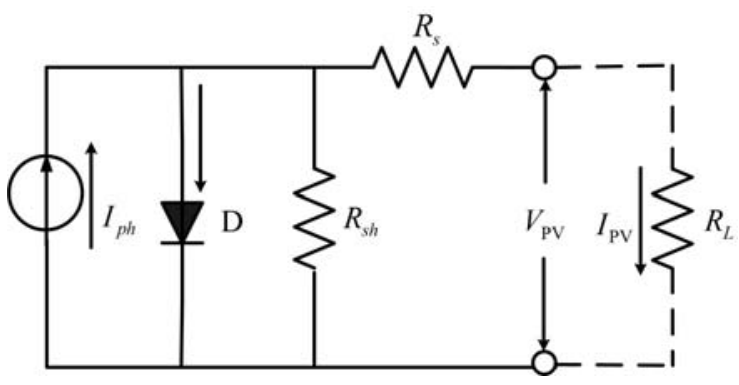

Figure 1. The equivalent circuit of PV cell model. 
In Figure 1 the output terminal current $I_{P V}$ may be described by (1)

$$
I_{P V}=I_{p h}-I_{D}=I_{p h}-I_{s a t}\left[\exp \left(\frac{q V_{p v}}{A K T}\right)-1\right]
$$

Where $I_{p h}$ is the short circuit current of module under a given solar irradiance (A); $I_{P V}$ is the terminal current of a module (A); $V_{P V}$ is the terminal voltage of a module. $q$ is the coulomb constant $\left(1.6 \times 10^{-19} \mathrm{C}\right) ; K$ is the Boltzmann's constant $\left(1.38 \times 10^{-23} \mathrm{~J} /{ }^{\circ} \mathrm{K}\right) ; T$ is the cell temperature $\left({ }^{\circ} \mathrm{K}\right) ; A$ is the ideal constant; $I_{\text {sat }}$ is the diode saturation current (A).

From (2) the output power of PV module $P_{P V}$ can be represented by

$$
P_{P V}=I_{P V} V_{P V}=I_{p h} V_{P V}-I_{s a t} V_{P V}\left(\exp \left(\frac{q V_{P V}}{A K T}\right)-1\right)
$$

\subsection{Integration of dynamic photovoltaic model}

The Solar PV Unit dynamic model was developed to simulate performance of a photovoltaic (PV) plant connected to the grid via a power converter. The model is largely based on the generic type 4 wind model, WT4, with the added ability to simulate output changes due to solar irradiation. The model is then incorporated with the power converter/generator module and electrical control module of Type 4 wind plant available in the PSS/E library [9]. The reason for using the Type 4 wind power model is PV plants are connected to the grid using the same technology used by Type 4 wind farm. From the point of DC-link to the grid connection, both PV and Type 4 wind technology use similar control and inverter technology to inject power to the grid $[9,10]$.

Figure 2 shows the PV Generic Model comprises the following modules:

- PVGU: power converter/generator module

- PVEU: electrical control module

- PANEL: linearized model of a panel's output curve

- IRRAD: linearized solar irradiance profile

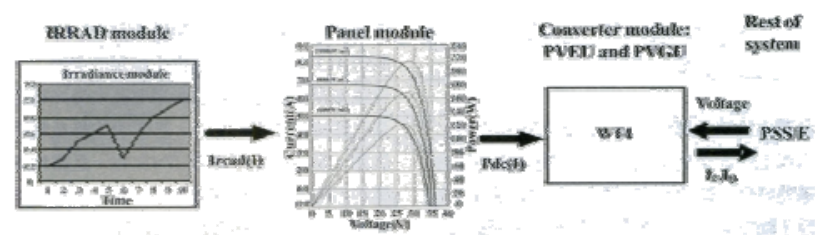

Figure 2. PV model connectivity diagram.

The modules are conventionally designated as wind modules with PVGU as the generator/converter module, PVEU as the electrical control module, PANEL as the mechanical module, and IRRAD as the pitch module. The power converter/generator module calculates the current injection to the grid based on filtered active and reactive power commands from the electrical control module as shown in Figure 3 and Figure 4 [9]. The reactive control calculates the reactive current command for the various control options, which could be any of the following:

- Remote bus voltage control

- Power factor control

- Reactive power control

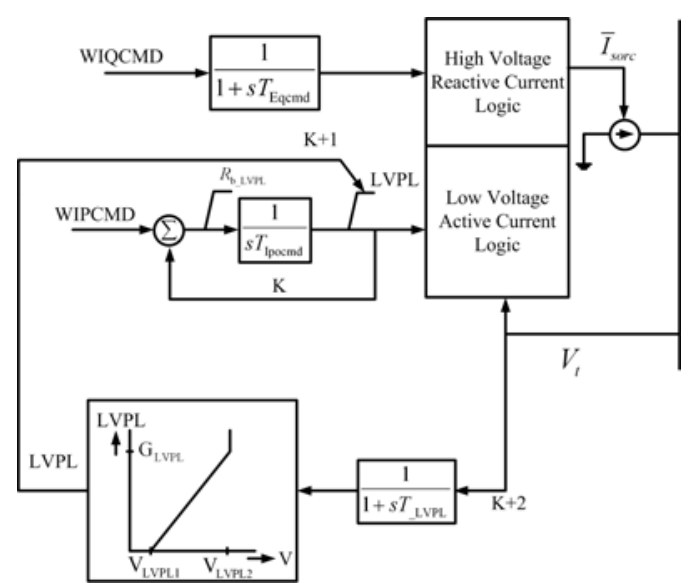

Figure 3. Power converter/generator module (PVGU).

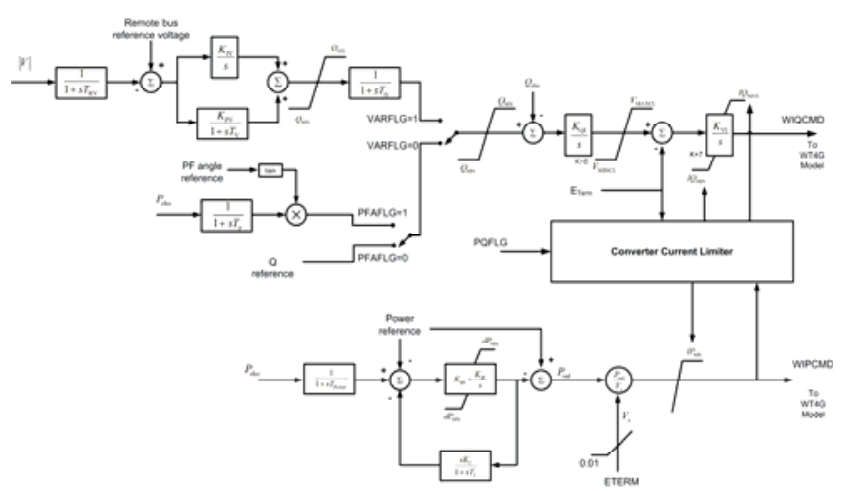

Figure 4. Electrical control module (PVEU).

\section{System dynamics}

\subsection{Study system}

In this paper, both system A and system B are taken as the study system of which both the investigation of incorporating PV generation on system dynamic characteristics and the effect of the changes in solar illumination. The single-line diagrams are shown in Figure 5 and Figure6.

The PV generations in the system $\mathrm{A}$ is divided into four groups, and use a step-up transformers $22.8 / 161 \mathrm{kV}$ up to $161 \mathrm{kV}$. The PV generation in the system B is integrated into the $161 \mathrm{kV}$ bus through a substation. 


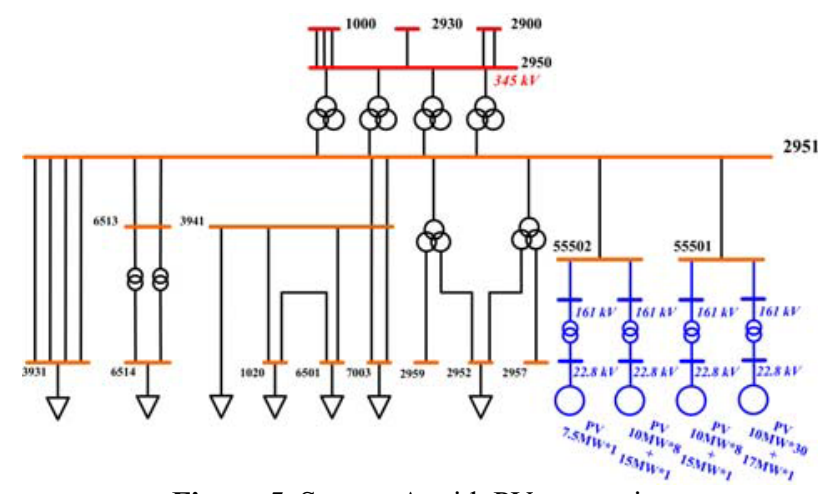

Figure 5. System A with PV generation.

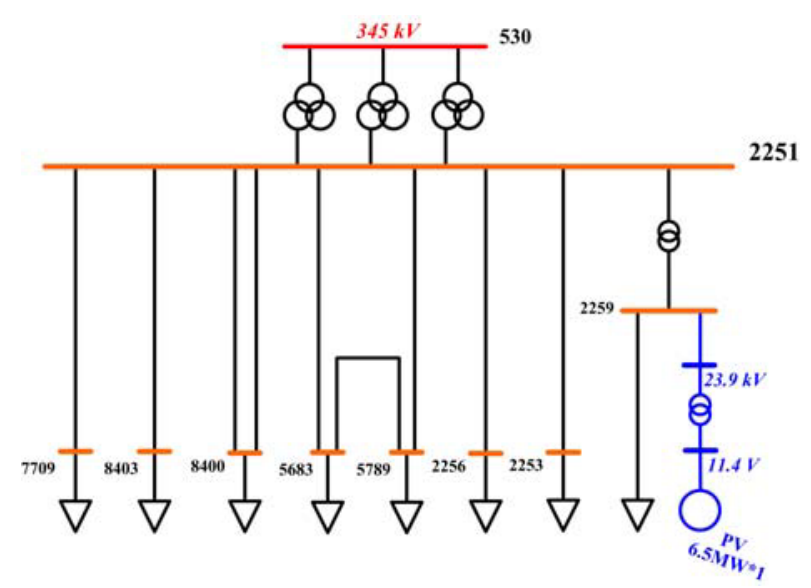

Figure 6. System B with PV generation.

\subsection{Simulation result}

When the disturbance applied to the system, the solar irradiation is set to constant $\left(1000 \mathrm{~W} / \mathrm{m}^{2}\right)$. The simulation work to be conducted starts with a three-phase short circuit fault set to occur at bus 2951 and cleared after 4 cycles. Figure 7 to Figure 10 show the responses of PV generation terminal voltage, active power, and the reactive power, respectively. From Figure 7 to Figure 9, due to that the a three-phase short circuit fault set to occur at $161 \mathrm{kV}$ bus 2951 , so the voltage response of bus 2951 drops more severe than another buses during a grid fault. Figure 10 shows the simulation results for the active power and reactive power of one PV generation. It can be observed that the PV generation provides the necessary reactive power compensation during system fault transient.

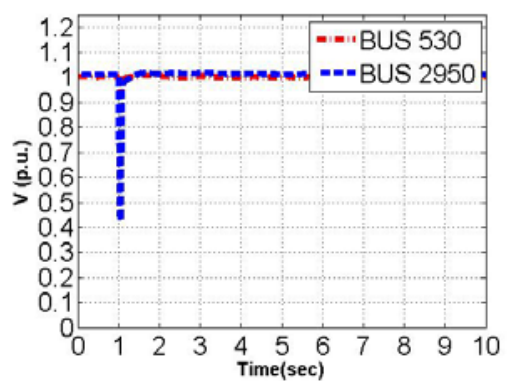

Figure 7. $345 \mathrm{kV}$ voltage responses of sample power system with PV generation.

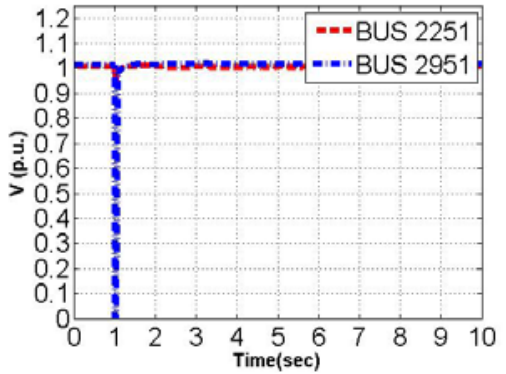

Figure 8. $161 \mathrm{kV}$ voltage responses of sample power system with PV generation.

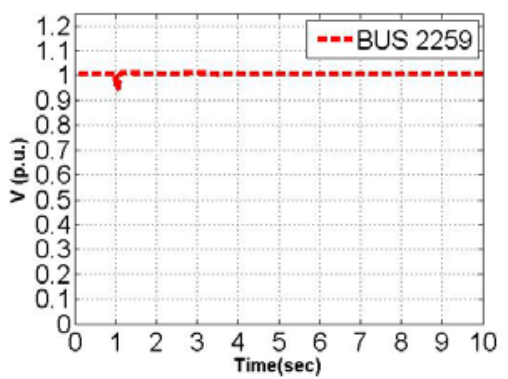

Figure 9. 23.9kV voltage responses of sample power system with PV generation.

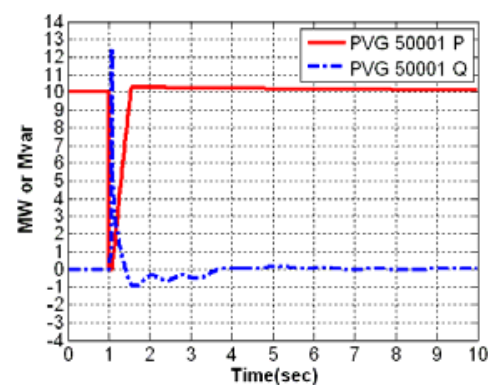

Figure 10. Active power and reactive power of PV generation.

PV generation is characterized as an intermittent source of energy as it is dependent on the environmental conditions. In this case, dynamic analysis is performed on the power system with PV generation under different illumination. The illumination is dropped from $1000 \mathrm{~W} / \mathrm{m}^{2}$ to $0 \mathrm{~W} / \mathrm{m}^{2}$ in 10 minutes and restored the illumination to $1000 \mathrm{~W} / \mathrm{m}^{2}$ in $5,10,30,60$ minutes, respectively. Figure 11 shows the active power responses are changed due to the changes in illumination. It is found from Figure 12 and Figure 17 that the illumination change does affect both voltage and frequency of the system.

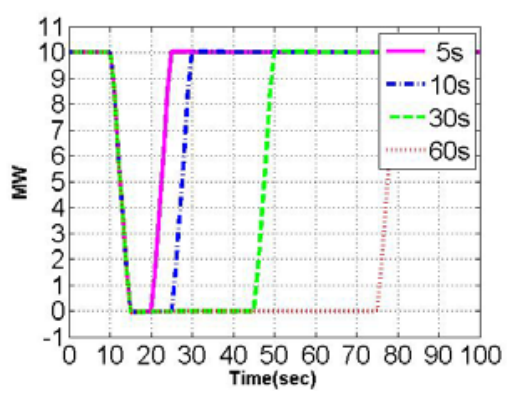

Figure 11. Active power for changes of illumination at PV generation. 


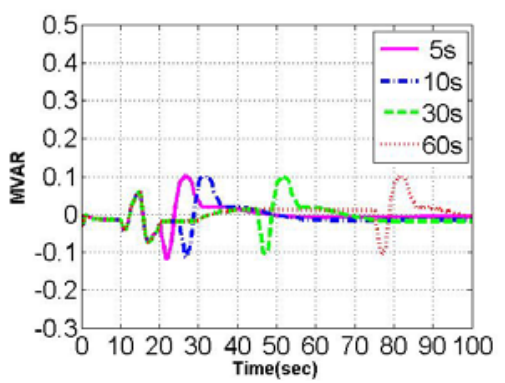

Figure 12. Reactive power for changes of illumination at PV generation.

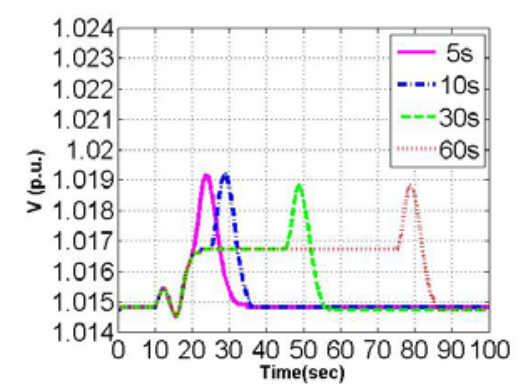

Figure 13. Voltage responses for changes of illumination at PV generation.

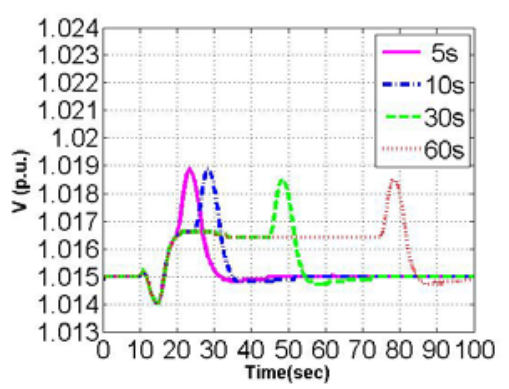

Figure 14. Bus 2951 voltage responses for changes of illumination.

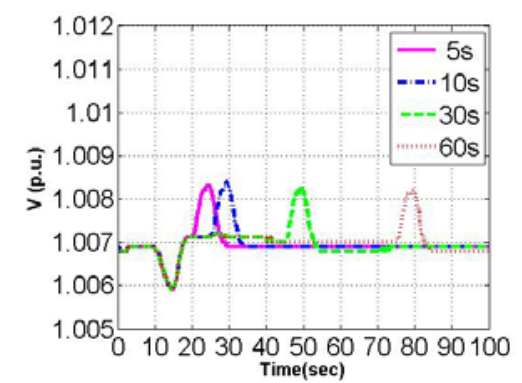

Figure 15. Bus 2259 voltage responses for changes of illumination.

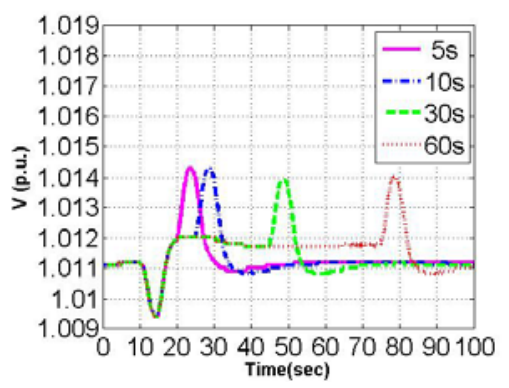

Figure 16. Bus 2950 voltage responses for changes of illumination.

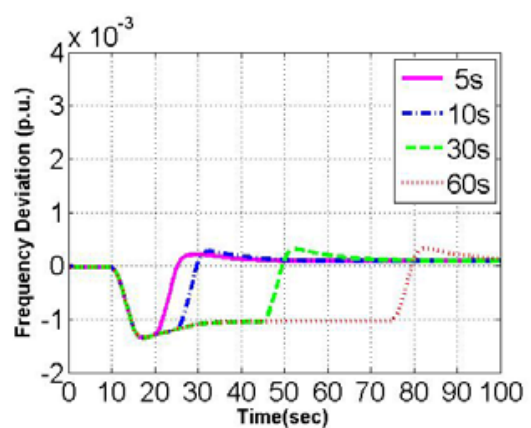

Figure 17. Bus 2951 frequency responses for changes of illumination.

\section{Conclusion}

The main purpose of this paper is to study the investigation of system dynamic characteristics with PV generation. The dynamic characteristics of the system are studied by simulating a three phase fault, and by changing the illumination. The demonstrated results show that PV generation provides the necessary reactive power compensation during system fault transient. The responses obtained from the studies indicate that the illumination change does affect both voltage and frequency of the system, and the system will return to a normal operating state after a period of time. The study results will be helpful to the practices of operation for the PV generation system

\section{Acknowledgements}

This work was supported in part by Ministry of Science and Technology under Grant MOST 104-2221-E-019025 and MOST 105-3113-E-194-003.

\section{References}

1. G. Boyle, Renewable Energy (Oxford, 2004)

2. R. Foster, M. Ghassemi, and A. Cota, Solar energy: Renewable Energy and the Environment (CRC Press, 2010)

3. B. Tamimi, C. Canizares, and K. Bhattacharya, IEEE T. Sustain. Energ., 4, 680-688 (2013)

4. A. R. Aarathi and M. V. Jayan, in Proceedings of 2014 International Conference on Advances in Green Energy, 26-32 (2014)

5. W. De Soto, S. A. Klein, and W. A. Beckman, Sol. Energy, 80, 77-88 (2006)

6. Y. B. Wang, C. S. Wu, H. Liao, and H. H. Xu, in Proceedings of IEEE International Conference on Industrial Technology, 1-6 (2008)

7. S. A. Kalogirou, Solar Energy Engineering: Processes and Systems (Elsevier, 2014)

8. R. A. Messenger and J. Ventre, Photovoltaic Systems Engineering (CRC Press, 2004)

9. Siemens Power Technology International, $P S S / E$ Version 33.4 Program Operation Manual (2013)

10. T. Alquthami, H. Ravindra, M. O. Faruque, M. Steurer, and T. Baldwin, in Proceedings of IEEE North American Power Symposium, 1-8 (2010) 